\title{
DISCURSO Y PRÁCTICA MÉDICOS FRENTE A LA PESTE EN LA EUROPA BAJOMEDIEVAL Y MODERNA*
}

\author{
Jon ARRIZABALAGA* \\ Institució «Milà i Fontanals». Barcelona
}

\begin{abstract}
Resumen
Este trabajo examina a grandes rasgos el discurso y la práctica de los médicos universitarios frente a la peste como paradigma de enfermedad epidémica de alta letalidad. Frente a concepciones fuertemente arraigadas en la historiografía, se subraya el carácter esencial del papel jugado por la medicina universitaria en la articulación de la lucha de las colectividades europeas bajomedievales y modernas frente a las enfermedades epidémicas.
\end{abstract}

\begin{abstract}
This paper briefly examines university physicians' discourse and practice in the face of plague as a paradigm of epidemic disease of high letality. In contrast to historiographical assumptions firmly rooted, it emphasizes the essential role played by university medicine to articulate the fightings of late medieval and early modern European colectivities against epidemic disease.
\end{abstract}

\section{INTRODUCCIÓN}

La enfermedad actualmente conocida como peste forma parte del capítulo de infecciones causadas por el grupo bacteriano conocido como Yersinia (antiguamente Pasteurella) y se define como una enfermedad infecciosa de roedores salvajes y domésticos, transmisible a los seres humanos a través de la picadura de ectoparásitos

* Investigador del CSIC. Dept. d'Història de la Ciència. Institució «Milà i Fontanals». Barcelona

**: Este trabajo fue originariamente presentado al Taller Epidèmia, contagi i responsabilitat política: de la febre groga a la SIDA celebrado en el Llatzeret de Maó entre los días 18 y 20 de setiembre de 1996. Una versión anterior del mismo fue publicada bajo el título «La peste y el discurso médico» en Historia 16 , 21/247, Noviembre 1996, pp. 52-58, dentro de la sección monográfica El miedo a la peste (pp. 49-75). 
(particularmente la pulga de la rata). La mayoría de los historiadores de la epidemiología está de acuerdo en que la peste ha asaltado de forma repetida las comunidades humanas a través de tres largos ciclos temporales o pandemias. El primer ciclo conocido se extendió entre el siglo VI, cuando tuvo lugar el estallido de la llamada «Peste de Justiniano», descrita por Procopius (542), y el VIII. La segunda pandemia duró desde 1300 hasta 1800 , y sus jalones inicial y final en Europa fueron la Peste Negra de 1348 y la Peste de Marsella (1720-1721), respectivamente. El tercero y último ciclo de peste comenzó en Asia Central hacia mediados del siglo XVIII y, como resultado de los reservorios de peste en los roedores campestres, continúa provocando casos esporádicos de peste humana en todos los continentes excepto Europa a la que sólo ha afectado de forma muy tangencial (Carmichael, 1993).

Tradicionalmente, la historia de esta enfermedad se ha escrito de acuerdo a su conceptualización médica actual, obviando la radical historicidad que encierra el término «peste». En otras palabras, se ha tendido a pasar por alto que esta etiqueta refleja una construcción intelectual herencia de la llamada «medicina de laboratorio»-la nueva medicina surgida en Occidente a lo largo del siglo XIX-- y, más en concreto, de la teoría bacteriológica. De ahí que, con demasiada frecuencia, los términos latinos pestis y pestilentia presentes en las fuentes histórico-médicas se hayan identificado, de forma más o menos automática, con la entidad específica que la medicina científica occidental conoce actualmente como «peste». Sin embargo, con anterioridad a la era bacteriológica los médicos aplicaban estos términos de forma indistinta a cualquier enfermedad epidémica que provocara una alta mortalidad entre las poblaciones humanas. Por todo ello resulta de todo punto imposible establecer una identidad entre las caracterizaciones prebacteriológicas y la actual de la peste, al tratarse de conceptos inconmensurables por responder a criterios definitorios radicalmente dispares (Cunningham, 1991; Arrizabalaga, 1992).

La irrupción de la Peste Negra de 1348 y los estallidos sucesivos de ésta y otras pestilencias durante los siglos XIV y XV hicieron cristalizar en el seno de las ciudades y estados europeos más dinámicos diversas estrategias de lucha contra las enfermedades epidémicas. Estas medidas sanitarias se difundieron de forma gradual por toda Europa y mantuvieron su vigencia, cuando menos, hasta el surgimiento de la salud pública sensu stricto en las últimas décadas del siglo XVIII y primeras del XIX.

En este trabajo examinaré a grandes rasgos el discurso y la práctica de los médicos universitarios frente a la peste como paradigma de enfermedad epidémica de alta letalidad. Frente a concepciones fuertemente arraigadas en la historiografía, subrayaré el carácter esencial del papel que la medicina universitaria jugó en la articulación de la lucha de las colectividades europeas bajomedievales y modernas frente a las enfermedades epidémicas.

\section{LA MEDICALIZACIÓN DE UNA CALAMIDAD SOCIAL}

Las crónicas de la época describen la Peste Negra de 1348 primaria y esencialmente como una gravísima calamidad más (junto a inundaciones, terremotos), que azotó a las distintas colectividades humanas dejando tras de sí un rastro de muerte y desolación (López de Meneses, 1956). Desde su estallido epidémico esta calamidad social experimentó a manos de la medicina universitaria una «medicalización» gradual, tanto en términos del carácter específico de la asistencia prestada a quienes la 
padecían, como de las interpretaciones al uso acerca de su naturaleza y causas. Aunque la imagen médica de la peste experimentó, durante los 400 años en que la segunda pandemia estuvo presente en Europa, cambios notables en función sobre todo de las corrientes intelectuales dominantes en la medicina de cada lugar y momento, el modelo teórico que guió las actuaciones de los médicos de formación universitaria durante todo este periodo permaneció en lo esencial constante (Hirst, 1953: 1-100).

En términos generales, los médicos universitarios bajomedievales y modernos abordaron la peste como un problema médico, y lo hicieron con la ayuda de los recursos intelectuales y técnicos de que disponían, a saber, una formación de carácter universitario, que estaba cimentada en un sistema médico (el galenismo en sus diferentes versiones hasta finales del siglo XVI y, a partir de entonces, en forma crecientemente residual, combinado con teorías renovadoras como la iatroquímica, la iatromecánica y otras); la experiencia médica previa, propia y ajena, frente a las enfermedades epidémicas de carácter mortífero; y la autoridad de los médicos antiguos (griegos y romanos), medievales (bizantinos, árabes y latinos) y modernos, por los que se inclinaban sus preferencias.

Por «peste» 0 «pestilencia» la mayoría de estos médicos entendía una condición universal del aire atribuible a «causas celestes», si bien el énfasis puesto en estas causas varió conforme a coordenadas espacio-temporales, y el interés por las mismas disminuyó de forma gradual y continuada en el transcurso de la Edad Moderna.

De acuerdo a la cosmovisión cristiana, incuestionable en Europa hasta bien entrado el siglo XVIII y de la que también participaban el Islam y el Judaísmo (los otros dos grandes monoteísmos presentes en el área mediterránea), la causa primera de la peste y de todas las demás cosas de la Creación era la voluntad de Dios. Ahora bien, tras la construcción por parte de los filósofos naturales cristianos de la idea de un orden natural regido de forma autónoma por leyes naturales, salvo en circunstancias excepcionales (los milagros), a los médicos cristianos les correspondía ocuparse de las causas segundas de la salud y la enfermedad humanas, y dejar para los teólogos el monopolio intelectual y profesional sobre el Primum Movens. Por lo demás, la teoría de las constelaciones de Albumasar fue su punto de referencia constante para explicar el permanente influjo ejercido por el macrocosmos sobre el microcosmos; y los conceptos aristotélicos de generación y corrupción (movimientos polares básicos en el mundo sublunar), el nervio de todas sus interpretaciones concernientes al modo de irrupción y difusión de la peste.

Circunstancialmente, junto a las causas celestes (influjo de los diferentes planetas, signos zodiacales y cometas, entre otros), los médicos universitarios asignaban también un papel a las «causas terrestres» (exhalaciones telúricas o hídricas) en la génesis de la peste. El recurso a estas causas era particularmente socorrido cuando había que explicar una epidemia circunscrita a un área más limitada.

Finalmente, también se contemplaba la posibilidad de causar la peste mediante artificio humano. Esta idea, que permitía proyectar sobre chivos expiatorios concretos la angustia social generada por la presencia de una epidemia mortífera, fue utilizada políticamente, como lo sigue siendo en la actualidad, para alimentar la estigmatización de distintos grupos sociales. El caso más conocido históricamente rememora el destacado papel de ciertos médicos universitarios en las acusaciones contra los untori con motivo de la peste milanesa de 1630 que constituye el marco de la novela de 
Alessandro Manzoni I promessi sposi, pero ya en 1348 hay testimonios que acreditan la existencia de similares imputaciones contra la minoría judía en círculos médicos de Montpellier (Guerchberg, 1948; Hirst, 1953: 18-21; Arrizabalaga, 1991: 97-101; Amasuno, 1996: 41-48).

La condición universal del aire definida como peste implicaba un cambio contranatural en la substancia de este elemento primario, es decir, su corrupción. Dado que el aire era considerado como el elemento vital más básico, los efectos de esta supuesta corrupción habían de ser casi infaliblemente masivos; de no ser así, por lo general se negaba la existencia de una «verdadera peste». Así pues, más que una enfermedad en sí misma, la peste era la causa de numerosos y diversos efectos derivados de la corrupción masiva de las cosas vivas en el mundo sublunar, entre los cuales se contaban diversas afecciones. Así, por ejemplo, en 1348 el profesor de la facultad de medicina de Lérida Jacme d'Agramont (fallecido en 1348) aseguraba que la pestilència afectaba sucesivamente a todos los seres de los «tres grados de vida» (árboles y plantas, animales y seres humanos) a través de la cadena alimentaria. Entre los efectos de aquélla Agramont destacaba «corrupciones, muertes súbitas y enfermedades diversas» (Veny i Clar, 1971: 52-53).

Desde 1348 los médicos universitarios se preocuparon también por establecer signos observables en el entorno físico, que permitieran augurar la irrupción o detectar la presencia de peste en un lugar determinado. En general, se trataba de fenómenos naturales inusuales referidos al aire y otros meteoros, a las plantas y animales, y al patrón local de enfermedades. Junto a estos signos, también asociaban de forma constante e inequívoca el mal olor del aire con la existencia de corrupción en este elemento, y ésta con el riesgo o la presencia de facto de la peste; una asociación que, como veremos, tuvo un amplio eco en el establecimiento de medidas preventivas cuyo objeto era eliminar cualquier fetor y, aún mejor, perfumar el ambiente con el pretendido propósito de reforzar su resistencia a la corrupción (Larrea Killinger, 1994).

Aunque el desencadenamiento de la peste era esencialmente impredecible porque dependía en última instancia de fuerzas macro y microcósmicas fuera del control humano, su potencial difusor estaba en razón directa con la cantidad de aire implicada en el proceso de corrupción. De ahí que la incorporación adicional de materia orgánica al proceso multiplicara las posibilidades de propagación de la peste. Algunos fenómenos atmosféricos naturales, como los vientos, aceleraban su difusión. Al mismo tiempo, las enfermedades que constituían efectos o accidentes suyos, se suponían en su mayor parte transmisibles a través de un contagio interpersonal por distintas vías, sobre cuya naturaleza (aliento, exhalaciones cutáneas, mirada, objetos personales, distancia) discutían los tratadistas en cada caso.

Hemos visto que la mayoría de los médicos convenían en que el aire era el vehículo de transmisión de la peste. Ahora bien, ya desde 1348 algunos de ellos comenzaron a preocuparse por la causa que hacía que cada pestilencia tuviera unas manifestaciones específicas y no otras. Para Gentile da Foligno (fallecido en 1348), cuando el aire corrupto de la peste penetraba en el interior de un cuerpo incapaz de resistir la corrupción, se generaba una «materia venenosa» junto al pulmón y corazón. Esta materia no actuaba por medio de las propiedades derivadas de la mezcla humoral $(\mathrm{com}$ plexio), sino mediante su «venenosidad», es decir, por su propiedad específica de ser venenosa. Gentile argüía cómo, por su poder de auto-multiplicación, esta materia ve- 
nenosa, incluso en muy pequeña cantidad, podía acabar infectando la totalidad del cuerpo, corrompiendo todos los órganos que alcanzara (incluido el corazón) hasta provocar la muerte. A su vez, los «vapores venenosos» exhalados por los cuerpos infectados provocaban la transmisión de la peste de una persona a otra y de un lugar a otro. De forma bien significativa, Gentile se hizo aquí eco del conocido párrafo del escrito De differentiis febrium en el que Galeno se refirió a «ciertas semillas de pestilencia» que son arrojadas por el cuerpo pestilente al aire circundante (Arrizabalaga, 1991: 103-105).

Estas ideas de Gentile, que implicaban una vaga noción de especificidad causal fueron, a todas luces, escasamente aceptadas en 1348. Ahora bien, en el transcurso de los siglos siguientes cobraron un peso siempre creciente en las interpretaciones de los médicos universitarios sobre las causas de la peste y otras enfermedades epidémicas. Si tradicionalmente los médicos universitarios pensaban que, en tiempo de peste, los individuos enfermaban porque el aire ambiente corrompido incidía sobre unos cuerpos cuya complexión se encontraba desequilibrada por un régimen de vida inadecuado, durante el siglo XV y comienzos del XVI aceptaron de forma gradual que los individuos también podían enfermar de peste como consecuencia de la actuación directa sobre sus cuerpos de la materia venenosa propia de esta enfermedad.

Tras la reformulación sistemática por Girolamo Fracastoro de las concepciones de Galeno sobre el contagio (1546) la idea de que estos individuos sólo enfermaban de cualquier enfermedad epidémica cuando entraban en contacto con su peculiar materia morbífica ganó de forma gradual adeptos entre los médicos de formación universitaria. En cualquier caso, esta materia venenosa no fue considerada causa suficiente de la peste hasta su reformulación en el marco de la doctrina bacteriológica a finales del siglo XIX. De ahí que, en las interpretaciones causales de la peste avanzadas por la mayoría de las corrientes médicas prebacteriológicas, se continuara requiriendo el concurso de otros grupos de causas muy similares, si no idénticos, a los propios del galenismo médico (Hamlin, 1992; Rodríguez Ocaña, 1995).

Ciertamente, los esfuerzos nosológicos de finales del siglo XVIII y comienzos del XIX posibilitaron un consenso creciente en torno a la idea de que las enfermedades epidémicas eran entidades morbosas específicas y no meras concreciones de una constitución epidémica general. Pero el consenso definitivo entre la comunidad médica sólo llegó con la difusión de la teoría bacteriológica (Hirst, 1953: 73-77). Hasta entonces su conceptualización había continuado siendo predominantemente «fisiológica» (Temkin, 1977), admitiéndose que una determinada causa podía ocasionar múltiples enfermedades y una determinada enfermedad podía deberse a múltiples causas; que los enfermos podían padecer enfermedades «mixtas"; y que en el curso de una determinada enfermedad la «materia morbífica» podía moverse libremente dentro del cuerpo enfermo, cambiar de asiento e incluso transformarse en materia propia de otra enfermedad (Cunningham, 1991; King, 1982; Nicolson, 1988; Codell Carter, 1993).

\section{LA PREVENCIÓN DE LA PESTE}

Desde el triunfo de la doctrina bacteriológica (décadas finales del siglo XIX y primeras del $\mathrm{XX}$ ) se ha tendido a representar la historia de las luchas sanitarias frente a las epidemias de peste en términos de dos estrategias antagónicas: las aeristas o miasmáticas (conocidas también como anticontagionistas) y las contagionistas, que 
supuestamente enfrentaron a los médicos universitarios entre sí, y a la mayoría de ellos con los responsables políticos de las colectividades (municipios, estados) europeas.

De acuerdo a estas concepciones, los «aeristas» defendían la difusión de la peste a través del aire corrompido (los «miasmas») y negaban la condición contagiosá de esta enfermedad, mientras los «contagionistas» limitaban los medios de propagación de la peste al contagio interpersonal o a través de bienes. Hasta la supuesta formulación de la teoría del «contagio vivo» por el médico humanista italiano Girolamo Fracastoro (1483-1553) las filas «aeristas» contarían entre sus adeptos a la inmensa mayoría de los médicos de formación universitaria, los cuales, cegados por su fidelidad a las autoridades médicas antiguas y árabes, habrían permanecido de espaldas a las medidas sanitarias «contagionistas» que las municipalidades y estados europeos más dinámicos promovieron durante los siglos siguientes a la Peste Negra de 1348, guiados por un «sano empirismo». Sólo a partir de Fracastoro algunos médicos comenzarían a oponerse a las tesis «aeristas» dominantes en la medicina universitaria, defendiendo el carácter contagioso de la peste e incorporando a su discurso estas decisivas novedades sanitarias que tiempo atrás habían puesto en práctica estas colectividades (Hirst, 1953: 33, 47-50).

En las dos últimas décadas esta difundida y persistente imagen historiográfica ha sido profundamente revisada. En efecto, se ha demostrado que la idea de contagio no fue ajena ni a Galeno, ni al galenismo latino bajomedieval y renacentista, y que el mérito de Fracastoro consistió no tanto en la presunta originalidad de su teoría, como en su logro sistematizador de las ideas sobre el contagio contenidas en los escritos galénicos, que reformuló en el marco del galenismo renacentista. La rápida y escasamente conflictiva difusión de la teoría de Fracastoro entre los médicos universitarios europeos de la segunda mitad del siglo XVI constituye una muestra planaria de la familiaridad de los contemporáneos con estas ideas (Nutton, 1983, 1990; Arrizabalaga, 1991).

Indudablemente, no puede negarse la existencia de una cierta tensión entre posiciones «aeristas» y «contagionistas» en los debates médicos suscitados en la Europa moderna con motivo de distintas epidemias. Ahora bien, en estos debates se ventilaban no tanto discrepancias conceptuales irreductibles en relación a la naturaleza de la enfermedad epidémica, como cuestiones de énfasis ligadas a las vicisitudes -específicas para cada escenario sociocultural y variables incluso en su seno en el trancurso del tiempo-del proceso de negociación de la enfermedad epidémica entre los diversos agentes sociales, entre los cuales los médicos universitarios jugaban un papel preponderante. Así pues, para la inmensa mayoría de los médicos prácticos de formación universitaria la difusión aérea y el contagio eran dos fases diferentes y sucesivas dentro del mismo proceso diseminador de la peste, y no medios alternativos y excluyentes entre sí (Hirst, 1953: 51-72). Sólo durante los dos primeros tercios del siglo XIX las disputas médicas sobre las causas de las enfermedades epidémicas se polarizaron de forma un tanto irreductible en torno a ambas posiciones (Ackerknecht, 1948).

Se ha podido también constatar que ante las epidemias bajomedievales y modernas de peste en Europa, no hubo discontinuidad o desconexión, sino estrecha interrelación entre las propuestas de los médicos universitarios y las medidas de prevención prescritas por los responsables políticos de municipios y estados, independientemente del signo de éstas. Un breve repaso de unas y otras es suficiente para apreciar esta interrelación. 
Ante la Peste Negra de 1348 los médicos universitarios habitualmente prescribieron medidas preventivas orientadas en tres direcciones diferentes y complementarias. En primer lugar, pretendían evitar o detener el proceso de corrupción del aire manteniendo habitaciones, casas y ciudades bien ventiladas y libres de basura, particularmente de estiércol y vísceras animales, por su gran facilidad para desencadenar este proceso; e igualmente eliminar el mal olor mediante la combustión de hierbas aromáticas y las fumigaciones de vinagre, al objeto de purificar el aire y reforzar su resistencia a la corrupción. En segundo lugar, intentaban mantener a los individuos refractarios al mal mediante el régimen de vida más adecuado para neutralizar la natural proclividad de su complexión a la corrupción humoral, junto a algunos antídotos específicos de eficacia probada. Finalmente, una vez desencadenada la epidemia, recomendaban eludir cualquier ocasión de transmisión interpersonal de la misma con medidas prácticas que iban desde la evitación de las aglomeraciones hasta el seguimiento del popular consejo -caricaturizado ad nauseam-fugere cito, longe, et tarde reverti («huye pronto y lejos, y regresa lo más tarde que puedas») (Arrizabalaga, 1994). Las modificaciones a estas medidas que introdujeron con ocasión de ulteriores epidemias obedecieron a un mero desarrollo cuantitativo de estas tres líneas directrices, por más que su sofisticación siempre fuera creciente.

Por su parte, las estrategias de lucha contra la peste y otras enfermedades epidémicas desplegadas por las autoridades políticas también crecieron de forma notable en sofisticación y número durante la Baja Edad Media y la Edad Moderna, pero sin desbordar nunca las coordenadas del discurso médico universitario. En términos generales, se trataba de medidas de conservación de la salud colectiva que se implantaban o reforzaban con motivo de la presencia o amenaza de epidemias y que podían ser de carácter ordinario (saneamiento urbano y socorro de pobres enfermos), o extraordinario (eliminación de malos olores para evitar la infección del aire; contratación de «médicos de peste» para reforzar el dispositivo sanitario; administración pública de triaca y otros supuestos antídotos frente a la enfermedad; imposición de cuarentenas a naves, viajeros y mercancías; establecimiento de lazaretos donde se confinaba a apestados y sospechosos de infección; y quema de los enseres y otras propiedades de éstos para eliminar los focos de infección y evitar la propagación de la misma, entre otras) (Rosen, 1993: 26-106; Ziegler, 1969; Gottfried, 1983; Biraben, 1975-1976; Cipolla, 1973, 1976, 1993; Palmer, 1978; Rubio Vela, 1979, 1994-95; Martínez Gomis, 1982; Slack, 1985; Carmichael, 1986; Henderson, 1989; Betrán, 1996).

Finalmente, parece evidente que el discurso médico universitario fue rápidamente aceptado por las élites políticas dominantes (García-Ballester, 1988, 1994; McVaugh, 1993), y desde el siglo XIV sirvió tanto de eje vertebrador de las medidas de prevención colectiva establecidas por ellas, como de elemento clave en la legitimación social de las mismas. La porción de tratados de peste encargados y/o dirigidos a las autoridades políticas desde la Peste Negra de 1348, y la presencia desde muy tempranas fechas de médicos universitarios en los órganos de poder político y en sus consejos de sanidad constituyen dos pruebas claras en favor de esta tesis.

Todo ello constituye, en resumidas cuentas, una muestra fehaciente de la prontitud y celeridad con que el nuevo saber médico y filosófico-natural que surgía de las universidades desde el siglo XIII, rebasó los límites del mundo académico y fue acogido por las ciudades y estados de la Europa bajomedieval y moderna como instru- 
mento válido para la articulación de respuestas, que fueron percibidas como socialmente eficaces, a sus demandas, en este caso, urgentes e inexcusables (García-Ballester, 1994).

\section{BIBLIOGRAFIA}

ACKERKNECHT, E.H. (1948), «Anticontagionism between 1821 and 1867», Bull. Hist. Med., 22, 562-593.

AMASUNO, M.V. (1996), La peste en la Corona de Castilla durante la segunda mitad del siglo XIV, Valladolid, Junta de Castilla y León.

ARRIZABALAGA, J. (1991), «La Peste Negra de 1348: los orígenes de la construcción como enfermedad de una calamidad social» en Dynamis, 11,73-117.

- (1992), «Nuevas tendencias en la historia de la enfermedad: a propósito del constructivismo social», Arbor, 142 (558-559-560), 147-165.

- (1994), «Facing the Black Death: perceptions and reactions of university medical practitioners». En: GARCÍA-BALLESTER, L.; FRENCH, R.K.; ARRIZABALAGA, J.; CUN NINGHAM, A. (eds.), Practical medicine from Salerno to the Black Death, Cambridge, Cambridge Univ. Press, pp. 237-288.

BETRÁN, J.L. (1996), La peste en la Barcelona de los Austrias, Lleida, Milenio.

BIRABEN, J.-N. (1975-1976), Les hommes et la peste en France et dans les pays européens et mediterranées (2 vols.), París-La Haya, Mouton.

CARMICHAEL, A.G. (1986), Plague and the poor in renaissance Florence, Cambridge, Cambridge Univ. Press.

- (1993), «Bubonic Plague». En KIPPLE, K.F. (ed.), The Cambridge World History of Human Disease, Cambridge, Cambridge University Press, pp. 628-631.

CIPOLLA, C.M. (1973), Cristofano and the plague. A study in the History of Public Health in the age of Galileo, Londres, Collins.

- (1976), Public Health and the Medical Profession in the Renaissance, Cambridge, Cambridge Univ. Press.

- (1993), Contra un enemigo mortal e invisible, Barcelona, Crítica.

CODELL CARTER, K. (1993), «Causes of Disease and Causes of Death» Trabajo presentado a la Conference on the History of Registration of the Causes of Death (Bloomington, University of Indiana, Noviembre 1993), organizada por G. ALTER, G. y A. CARMICHAEL ("working-papers publication").

CUNNINGHAM, A. (1991), «La transformación de la peste: el laboratorio y lá identidad de las enfermedades infecciosas», Dynamis, 11, 27-71 [versión inglesa: «Transforming plague: the laboratory and the identity of infectious disease», en CUNNINGHAM, A. y WILLIAMS, P. (eds.), The laboratory revolution in medicine, Cambridge, Cambridge Univ. Press, 1992, pp. 209-244].

GARCÍA-BALLESTER, L. (1988), La medicina a la València medieval. Medicina $i$ societat en un país medieval mediterrani, Valencia, Edicions Alfons El Magnànim.

- (1994), «Introduction: Practical medicine from Salerno to the Black Death», en GARCIABALLESTER, L.; FRENCH, R.K.; ARRIZABALAGA, J.; CUNNINGHAM, A. (eds.), Practical medicine from Salerno to the Black Death, Cambridge, Cambridge Univ. Press, pp. $1-29$. 
GOTTFRIED, R.S. (1983), The Black Death. Natural and human disaster in medieval Europe, Londres, Macmillan.

GUERCHBERG, S. (1948), «La controverse sur les prétendus semeurs de la "Peste Noire" d'après les traités de peste de l'époque», Revue des Études Juives, 108, 3-40 [versión inglesa: «The controversy over the alleged sowers of the Black Death in the contemporary treatises on plague», en THRUPP, S. (ed.), Change in medieval society. Europe North of the Alps, 1050-1500, Londres, 1965, pp. 208-224].

HAMLIN, C. (1992), «Predisposing causes and public health in early nineteenth-century medical thought», Social History of Medicine, 5(1), 43-70.

HENDERSON, J. (1989), «Epidemics in Renaissance Florence: Medical Theory and Government Response», en Maladies et societé (XII-XVIII siècles). Actes du Colloque de Bielefeld, París, CNRS, pp. 165-186.

HIRST, L.F. (1953), The conquest of plague. A study of the evolution of epidemiology, Oxford, Claredon Press.

KING, L.S. (1982), Medical Thinking. A Historical Preface, Princeton Univ. Press, Princeton.

LARREA KILLINGER, C. (1994), Los miasmas: antropología histórica de un concepto médico, Universidad de Barcelona, Tesis doctoral.

LÓPEZ DE MENESES, A. (1956), «Documentos acerca de la peste negra en los dominios de la Corona de Aragón», Estudios de Edad Media de la Corona de Aragón (Sección de Zaragoza), 6, 291-447.

MARTÍNEZ GOMIS, M. (1982), «La larga espera de la muerte en una ciudad valenciana del siglo XVII. (Orihuela ante la peste de 1676-1678)», Anales de la Universidad de Alicante. Historia Moderna, 2, 135-166.

McVAUGH, M.R. (1993), Medicine before the plague. Practitioners and their patients in the Crown of Aragon, 1285-1345, Cambridge, Cambridge University Press.

NICOLSON, M. (1988), «The Metastasic Theory of Pathogenesis and the Professional Interests of the Eighteenth-Century Physician», Medical History, 32, 277-300.

NUTTON, V. (1983), «The seeds of disease: an explanation of contagion and infection from the Greeks to the Renaissance», Medical History, 27, 1-34.

- (1990), «The reception of Fracastoro's theory of contagion: the seed that fell among thorns?», Osiris, 6, 196-234.

PALMER, R.J., The control of plague in Venice and northern Italy, 1348-1600, Canterbury, University of Kent, Tesis de Doctorado (inédita).

RODRÍGUEZ OCAÑA, E. (1995), «Medicina y epidemias. De la racionalización del mito al mito de la racionalización», en BARONA, J.L. (ed.), Malaltia $i$ cultura. Trobades, València, Seminari d'Estudis sobre la Ciència, pp. 207-224.

ROSEN, G. (1993), A history of public health [1958], $2^{a}$ ed., Baltimore-Londres, The Johns Hopkins University Press.

RUBIO VELA, A. (1979), Peste Negra, crisis y comportamientos sociales en la España del siglo XIV. La ciudad de Valencia (1348-1401), Granada, Universidad de Granada.

- (1994-1995), «Las epidemias de peste en la ciudad de Valencia durante el siglo XV. Nuevas aportaciones», Estudis Castellonencs, 6, 1.179-1.221.

SLACK, P. (1985), The impact of plague in Tudor and Stuart England, Oxford, Claredon (reimpr. con correcciones en 1990). 
TEMKIN, O. (1977), «The scientific approach to disease: specific entity and individual sickness» [1963]. En: The Double Face of Janus and Other Essays in the History of Medicine, Baltimore-Londres, The Johns Hopkins University Press, pp. 441-455.

VENY I CLAR, J. (1971), «Regiment de preservació de pestilència» de Jacme d'Agramont (s. $X I V)$. Introducció, transcripció $i$ estudi lingüistic, Tarragona, Diputación Provincial.

ZIEGLER, Ph. (1969), The Black Death, Londres, Collins (reimpr.: Harmondsworth, Penguin Books, 1982). 